\title{
Anthracycline Therapy and 24-Hour Blood-Pressure Profile in Long- Term Survivors of Childhood Cancer
}

\author{
Z. NOVÁKOVÁ ${ }^{1}$, J. ŠŤASTNÁ ${ }^{2}$, K. HONZÍKOVÁ ${ }^{2}$, H. HRSTKOVÁ ${ }^{2}$, N. HONZÍKOVÁ ${ }^{1}$, \\ E. ZÁVODNÁ ${ }^{1}$, B. FIŠER ${ }^{1}$, P. HONZÍK ${ }^{3}$
}

${ }^{1}$ Department of Physiology, Faculty of Medicine, Masaryk University, Brno, Czech Republic, ${ }^{2}$ Department of Pediatric Internal Medicine, Faculty Hospital Brno and Faculty of Medicine, Masaryk University, Brno, Czech Republic, ${ }^{3}$ Department of Control and Instrumentation, Brno University of Technology, Brno, Czech Republic

Received February 9, 2010

Accepted March 26, 2010

\section{Summary}

In our previous studies, a decreased blood pressure was reported in children treated by anthracycline (AC). The aim of this study was to assess the long-term effects of $A C$ anticancer therapy in 45 subjects aged 13-22 years by repeated 24-hour Holter monitoring of blood pressure. Sixty four aged-matched subjects served as controls. The differences between mean values of systolic (SBP) and diastolic blood pressure (DBP) in each hour of both groups were evaluated by Mann-Whitney test. Also the parameters of the least-squares fit of the sinusoidal curve in each subject were estimated ( $M$ - mesor, midline-estimating, a mean value of sinusoidal curve corresponds to 24-hours mean pressure; A - amplitude, double amplitude corresponds to nightday difference; Acr - acrophase is a time of maximal value of a sinusoidal curve). SBP and DBP was significantly lower only during night hours in anthracycline patients 19-22 years old. Also $M$ was lower in this age subgroup of patients comparing to age matched controls (SBP: $112 \pm 6 \mathrm{~mm} \mathrm{Hg}$ versus $117 \pm 7 \mathrm{~mm} \mathrm{Hg}$, p<0.05; DBP: $67 \pm 3 \mathrm{~mm} \mathrm{Hg}$ versus $69 \pm 6 \mathrm{~mm} \mathrm{Hg}, \mathrm{p}<0.05)$, A was not different, Acr in patients was shifted one hour earlier (SBP: 2.4 p.m. versus 3.6 p.m., p<0.05; DBP: 2.1 p.m. versus 3.3 p.m., $p<0.01$ ). This corresponds to the shift of the morning blood-pressure increase seen on 24-hours blood pressure profiles. $M$ correlated with age in controls (SBP: $r=0.374$, $\mathrm{p}<0.01$; regression coefficient $\mathrm{b}=1.34 \mathrm{~mm} \mathrm{Hg} / 1$ year; DBP: $r=0.365, p<0.01 ; b=0.95 \mathrm{~mm} \mathrm{Hg} / 1$ year), but not in patients (SBP: $r=0.182$, DBP: $r=0.064$ ). A and Acr were age-independent in all subjects. It is concluded that blood pressure in 19-22 years old AC patients is lower during night hours, the age-dependent increase of blood pressure seen in healthy controls between
13 and 22 years of age does not occur in patients. This finding is consistent with the long-lasting impairment of the sympathetic nervous system caused by anthracyclines.

\section{Key words}

Anthracyclines - Blood pressure - Cardiotoxicity - Childhood cancer • Chronobiology

\section{Corresponding author}

Z. Nováková, Department of Physiology, Faculty of Medicine, Masaryk University, Komenského nám. 2, 66243 Brno, Czech Republic. Fax: +420 549493748. E-mail: znovak@med.muni.cz

\section{Introduction}

Anthracycline chemotherapeutics proved a broad efficiency against a variety of childhood malignancies. Their use in children is beneficial and has led to a 5-year survival rate in nearly $80 \%$ (Jemal et al. 2006). However, this therapy affects the cardiovascular system in the longrun, and it has been documented that childhood cancer survivors have higher rates of congestive heart failure and cardiac death (Mertens et al. 2001, Oeffinger et al. 2006). Late anthracycline cardiotoxicity is associated primarily with reduced left ventricular function (Lipshultz et al. 2005, Elbl et al. 2006) or increased left ventricular afterload (Colan et al. 1992). The state-of-art of this research has been regularly reviewed (Giantris et al. 1998, Scully and Lipshultz 2007). 
Anthracyclines also interact with the autonomous nervous system: The complex changes in tonic and reflex heart rate regulation may be explained by the anthracycline-induced suppression of cholinesterase synthesis in the heart muscle with a subsequent increase in acetylcholine activity (Geršl et al. 1996). An interaction between the anthracyclines and the sympathetic nervous system was also reported (Sakai et al. 1998). As to systolic (SBP) and diastolic blood pressure (DBP) changes in long-term survivors of childhood cancer, remarkably few sorrow data exist. Merely both hypertension (Pai and Nahata 2000) and hypotension were uniquely noticed (Nováková et al. 2007).

In our previous study (Nováková et al. 2007), we examined blood pressure using continuous finger arterial blood pressure measurement by Finapres in children, adolescents, and young adults previously treated with anthracyclines and compared their blood pressure with healthy controls of the same age. These subjects were aged between 11 and 22 years and were examined twice in an interval between 1 and 9 years. Lower values of SBP and DBP were found in anthracycline treated patients. The age-dependent blood-pressure increase, which was present in healthy adolescents, was not found in cancer survivors in this study. Finapres has been validated in adults, but only few studies in paediatrics have been reported. The comparison of measurements of blood pressure by Finapres and by the auscultatory method was done by Tanaka et al. (1994) and Závodná et al. (2005a), and these measurements have similar accuracy as in adults. On the other hand the data of 24-hours SBP and DBP variations in anthracycline treatment survivors are missing.

The aim of this study was to compare the 24-hour Holter blood-pressure recordings in adolescents and young adults after anthracyclines cancer therapy with age-matched healthy controls.

\section{Methods}

\section{Subjects}

We examined 106 subjects (46 males). Fortytwo children and adolescents after anthracycline treatment for acute lymphoblastic leukaemia (18 males, 24 females) were compared with 64 age-matched healthy controls (28 males, 36 females). The patients received a total cumulative dose of $229 \pm 33(120-300) \mathrm{mg} / \mathrm{m}^{2}$ of anthracyclines. Cyclophosphamide, as part of the treatment protocol, was given to all patients in the total mean dose of $2829 \pm 376 \mathrm{mg} / \mathrm{m}^{2}$. The period between the end of the treatment and ambulatory blood pressure monitoring was $9.8 \pm 3.1$ (4-16) years. One patient was treated with additional mediastinal radiation (dose of 12 Gy). The main clinical characteristics of the studied population are shown in Table 1.

Table 1. The main clinical characteristics of the studied groups.

\begin{tabular}{|c|c|c|c|}
\hline Parameters & Group Co & Group A & $\mathbf{P}$ \\
\hline $\begin{array}{l}\text { Age } \\
\text { (years) }\end{array}$ & $17.8 \pm 2.4$ & $17.3 \pm 2.3$ & NS \\
\hline $\begin{array}{l}\text { Body weight } \\
(\mathrm{kg})\end{array}$ & $63.8 \pm 10.9$ & $61.2 \pm 13.8$ & NS \\
\hline $\begin{array}{l}\text { Body height } \\
(\mathrm{cm})\end{array}$ & $172.4 \pm 8.2$ & $166.7 \pm 9.5$ & $\begin{array}{l}<0 . \\
01\end{array}$ \\
\hline $\begin{array}{l}B M I \\
\left(\mathrm{~kg} / \mathrm{m}^{2}\right)\end{array}$ & $21.4 \pm 3.0$ & $21.9 \pm 3.6$ & NS \\
\hline $\begin{array}{l}\text { Period after } \\
\text { treatment } \\
\text { (years) }\end{array}$ & $9.8 \pm 3.1$ & & \\
\hline \multirow[t]{5}{*}{ Treatment } & $\begin{array}{l}\text { Anthracyclines } \\
\left(\mathrm{mg} / \mathrm{m}^{2}\right)\end{array}$ & $229.0 \pm 33.8$ & \\
\hline & $\begin{array}{l}\text { Vincristine } \\
\left(\mathrm{mg} / \mathrm{m}^{2}\right)\end{array}$ & $14.7 \pm 6.0$ & \\
\hline & $\begin{array}{l}\text { Cyclophosphamide } \\
\left(\mathrm{mg} / \mathrm{m}^{2}\right)\end{array}$ & $2829.3 \pm 376.3$ & \\
\hline & $\begin{array}{l}\text { RT } \\
(\mathrm{n})\end{array}$ & 1 & \\
\hline & $\begin{array}{l}\text { Dexrazoxane } \\
\text { (n) }\end{array}$ & 30 & \\
\hline
\end{tabular}

The values are presented as mean \pm standard deviation. Group Co - healthy controls, group A - patients treated with anthracyclines; BMI - body mass index; $\mathrm{P}$ - statistical analysis by Mann-Whitney test: Co versus A, NS - insignificant, $n$ - number of subjects, RT - radiotherapy of mediastinum.

All patients were diagnosed and treated at the First Department of Paediatric Internal Medicine, Faculty Hospital in Brno. Healthy subjects were recruited from volunteers at primary and secondary schools in Brno. All subjects (controls and patients), or their parents - (in patients under 18 years of age), gave their informed consent. The protocols of our study were approved by the ethics committee.

The subjects were divided into 3 subgroups according to age: 13-15 years (9 patients, 9 controls), 
16-18 years (19 patients, 33 controls), and 19-22 years (14 patients, 22 controls).

\section{Blood pressure measurement}

Twenty-four-hour monitoring of SBP and DBP was carried out by a Space Labs Medical-Holter recorder 90217 (Redmond, WA, USA). The device was programmed to take blood pressure measurements every $15 \mathrm{~min}$ from 6 to $22 \mathrm{~h}$ (daytime) and every $20 \mathrm{~min}$ from 22 to $6 \mathrm{~h}$ (night-time). The monitoring cuff was applied around the non-dominant arm in the morning. We compared the mean 24-hour profile of SBP and DBP between anthracycline-treated patients and healthy controls in each age group and determined the statistical significance of the differences in each hour by a nonparametric Mann-Whitney test. Also the parameters of the least-squares fit of the sinusoidal curve with a period of 24 hours (Cornélissen et al. 1990) in each subject were estimated: M - midline-estimation, the mean value of sinusoidal curve corresponds to 24-hours mean pressure; A - amplitude, double amplitude corresponds to nightday difference; Acr - acrophase is the time of maximum value of a sinusoidal curve. The age-dependent development of $\mathrm{M}, \mathrm{A}$, and Acr were recorded and analyzed in both anthracycline-treated and control subjects.

\section{Statistical analysis}

Results are presented as the mean \pm standard deviation (S.D.). Statistical analysis was performed by the STATISTICA software, version 6.0 (StatSoft, Inc.). The significance of differences between the controls and the patients was evaluated by the Mann-Whitney test. The Pearson's correlation coefficient was used for the other statistical evaluations.

\section{Results}

A comparison of the mean 24-hour profile of SBP and DBP between the anthracycline-treated patients and the healthy controls in each age group is shown in Figure 1 . The statistically significant difference between the anthracycline-treated patients and the controls was found during the night hours.

Parametric indices of blood-pressure variations derived from 24-hour recordings using the least-squares fit of the cosine curve with a period of 24 hours for all age groups are in Table 2. A significant correlation between $\mathrm{M}$ and age was found in the controls as seen in
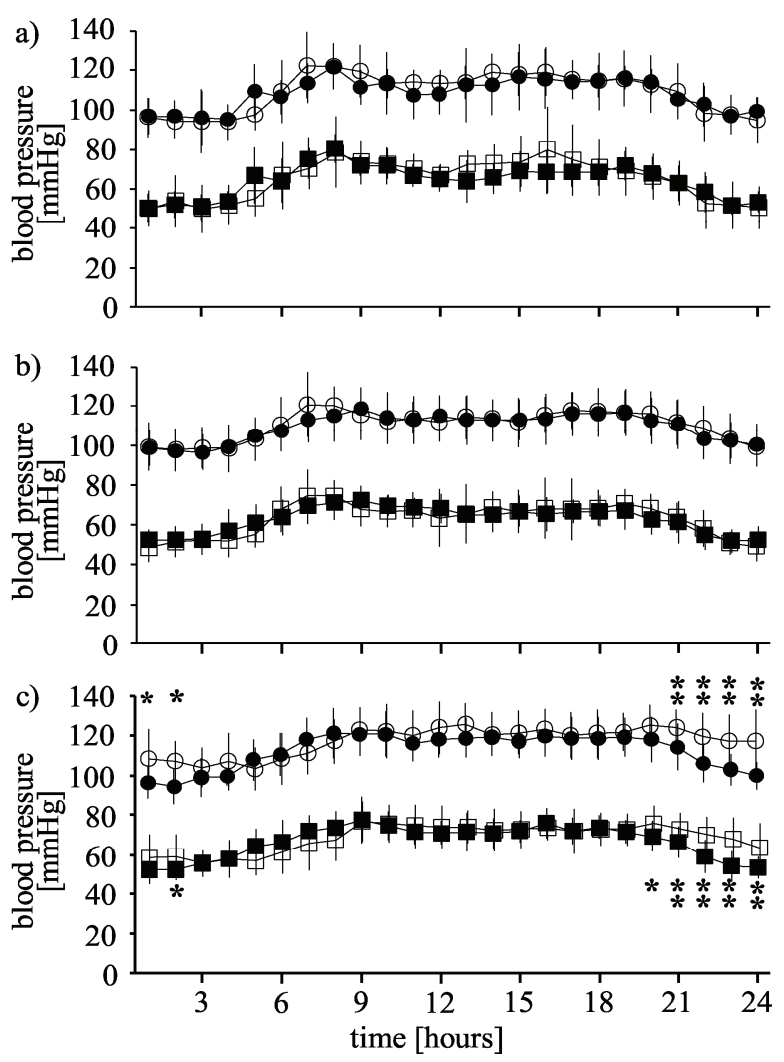

Fig. 1. The mean 24-hour profiles of blood pressures in age subgroups. a): subgroup $13-15$ years; b): subgroup $16-18$ years; c): subgroup 19-22 years. Full circles - systolic blood pressure, squares - diastolic blood pressure, open symbols - controls, full symbols - patients treated with anthracyclines; $* p<0.05$, $* * p<0.01$.

Figure 2 but not in the anthracycline-treated patients (SBP: $r=0.182$, DBP: $r=0.064$ ). A and Acr were ageindependent. $\mathrm{M}$ values of SBP and DBP were lower in treated patients in the age group of 19-22 years in comparison with controls of the same age. In the group of 19-22 years old, Acr appeared one hour earlier in treated patients. This finding corresponds to the shift of the early-morning blood-pressure increase seen on the mean 24-hour blood pressure profile of the anthracyclinetreated patients in this age group (Fig. 1c). No significant differences in A between the two groups were ascertained.

\section{Discussion}

The late adverse side effects of anticancer therapy in children develop during decades in their later life (Simbre et al. 2005). Cardiac injury may occur as a side effect of anthracycline treatment many years after the initial treatment (Mott 1997), namely in patients with underlying risk factors, though not in all. The most 
Table 2. 24-h based parametric indices of blood pressure variation.

\begin{tabular}{|c|c|c|c|c|c|c|c|}
\hline \multirow{3}{*}{$\begin{array}{c}\text { Age } \\
13-15\end{array}$} & \multicolumn{2}{|c|}{ Parameters } & \multicolumn{2}{|c|}{ Group Co } & \multicolumn{2}{|c|}{ Group A } & \multirow[t]{2}{*}{$\mathbf{P}$} \\
\hline & & & mean & \pm S.D. & mean & \pm S.D. & \\
\hline & SBP & M & 109.9 & 10.4 & 108.4 & 8.5 & NS \\
\hline \multirow[t]{5}{*}{ years } & & A & 11.5 & 2.5 & 9.4 & 5.0 & NS \\
\hline & & Acr & 1.3 & 3.6 & 2.5 & 1.5 & NS \\
\hline & DBP & M & 63.7 & 6.8 & 65.0 & 7.2 & NS \\
\hline & & A & 12.5 & 8.9 & 9.1 & 3.9 & NS \\
\hline & & Acr & 0.6 & 3.8 & 0.9 & 1.5 & NS \\
\hline $16-18$ & SBP & M & 111.0 & 8.1 & 109.2 & 8.5 & NS \\
\hline \multirow[t]{5}{*}{ years } & & A & 8.9 & 4.3 & 9.3 & 3.0 & NS \\
\hline & & Acr & 1.8 & 4.4 & 3.1 & 1.8 & NS \\
\hline & DBP & M & 64.3 & 5.4 & 63.9 & 6.5 & NS \\
\hline & & A & 9.0 & 4.0 & 10.9 & 11.1 & NS \\
\hline & & Acr & 1.4 & 3.6 & 1.6 & 0.9 & NS \\
\hline $19-22$ & SBP & M & 117.0 & 7.0 & 112.3 & 5.8 & $<0.05$ \\
\hline \multirow[t]{5}{*}{ years } & & A & 9.4 & 5.0 & 11.2 & 4.5 & NS \\
\hline & & Acr & 3.6 & 2.3 & 2.4 & 1.3 & $<0.05$ \\
\hline & DBP & M & 69.0 & 6.0 & 66.6 & 3.4 & NS \\
\hline & & A & 9.0 & 3.8 & 10.0 & 3.3 & NS \\
\hline & & Acr & 3.3 & 1.8 & 2.1 & 2.8 & $<0.01$ \\
\hline
\end{tabular}

The values are presented as mean \pm standard deviation (S.D.); MESOR (M) and AMPLITUDE (A) in $\mathrm{mm} \mathrm{Hg}$, ACROPHASE (Acr) in hours p.m. Group Co - healthy controls, group A - patients treated with anthracyclines; SBP, DBP - systolic and diastolic blood pressures, $\mathrm{P}$ - statistical analysis by Mann-Whitney test: group Co versus group A, NS - insignificant.

frequent cardiac dysfunction is characterized by depressed left ventricular function related to depressed contractility or by increased afterload. These subjects are at risk of late congestive heart failure and of cardiac mortality due to pump failure. There are also other deficiencies caused by anthracyclines, or other anticancer therapy respectively, as for example dyslipidaemia (Adams and Lipshultz 2005, Závodná et al. 2005b, Scully and Lipshultz 2007), elevated of serum cardiac troponin T level (Cardinale et al. 2006, Scully and Lipshultz 2007), electrocardiographic abnormalities (Mladosievičová et al. 2001), or neurohumoral activation (Horáček et al. 2005).

Late effects of anticancer therapy in children, adolescents, and young adults from the Brno region have been examined for many years (Hrstková et al. 2001, 2003, Závodná et al. 2002). Except for diastolic and systolic dysfunction, dyslipidaemia and decrease of physical activity was reported (Elbl et al. 2005, 2006,

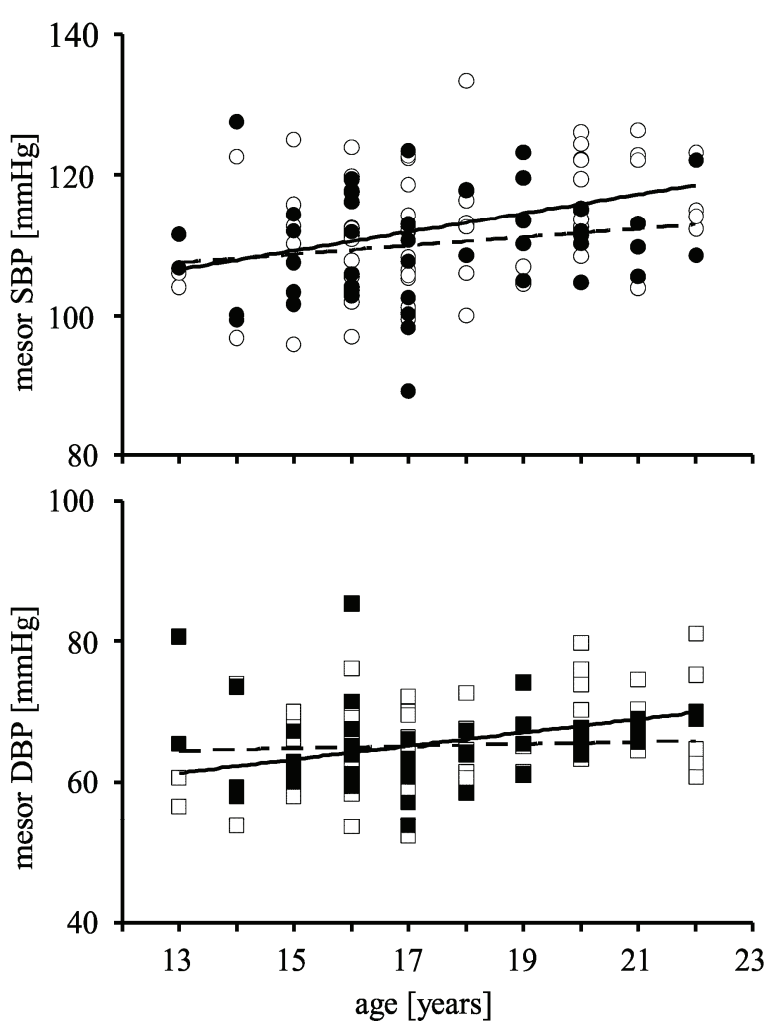

Fig. 2. Correlation between MESOR values of SBP and DBP and age in patients and healthy controls. SBP - systolic blood pressure, DBP - diastolic blood pressure, open symbols - controls, full symbols - patients treated with anthracyclines; full lines significant correlation $(p<0.01)$ in controls, dashed lines insignificant relationship in patients.

Balcárková et al. 2006, Balcárková et al. 2008). In our study (Nováková et al. 2007) we did not find any changes of parasympathetic functions estimated by repeated measurements of baroreflex sensitivity. However, a decrease of blood pressure was obvious. This result, based on repeated 5-minute continual measurement of blood pressure from the digital artery (Peňáz method), was verified in the present study by 24-hour blood pressure measurement: in the group of children and adolescents under 18 years of age the differences in blood pressure were not significant when comparing controls and survivors of anticancer therapy (i.e. no physiological age-related blood-pressure increase). In contrast, in the group of young adults, a significantly lower mesor of systolic blood pressure was present. Evaluation of the 24-hour blood pressure profile indicated that the bloodpressure decrease was present at night and was significant in both systolic and diastolic blood pressures. In our previous study (Nováková et al. 2007) we also showed that baroreflex heart-rate sensitivity did not differ between controls and survivors of anticancer therapy; therefore we suppose that the blood-pressure decrease 
could be related to reduced sympathetic nervous activity. Our findings of impaired blood pressure control and unchanged baroreflex control of the heart are in agreement with the study of heart rate and blood pressure variability in patients after anthracycline-treated breast cancer, which demonstrated an unchanged vagal cardiac control, but altered vascular control (Ekholm et al. 2000). This finding is consistent with the impairment of the sympathetic nervous system in rat arteries caused by anthracycline toxicity (Sakai et al. 1998).

It is concluded that the blood pressure in 19-22 years old anthracycline treated patients is significantly lower with respect to controls during night hours and that increase of blood pressure characteristic for healthy controls between 13 and 22 years of age does not occur in anthracycline treated patients. This finding is consistent with anthracycline-induced long-lasting decay of the sympathetic nervous system.

\section{Conflict of Interest}

There is no conflict of interest.

\section{Acknowledgements}

This study was supported by grants No. MSM 0021622402 and MSM 0021630529.

\section{References}

ADAMS MJ, LIPSHULTZ SE: Pathophysiology of anthracycline- and radiation-associated cardiomyopathies: implications for screening and prevention. Pediatr Blood Cancer 44: 600-606, 2005.

BALCÁRKOVÁ P, HRSTKOVÁ H, ELBL L, NOVÁKOVÁ Z, ZÁVODNÁ E, HONZÍKOVÁ N, FIŠER B: Blood pressure and left ventricle function in patients treated with anthracyclines (in Czech). Klinická onkologie 19: 269-273, 2006.

BALCÁRKOVÁ P, ELBL L, NOVÁKOVÁ Z, HRSTKOVÁ H, VÍTOVEC J, ŠŤASTNÁ J, KRONTORÁDOVÁ K: Evaluation of left ventricle function in patients treated for malignancy in last years (in Czech). Cor Vasa 50: 378-384, 2008.

CARDiNALE D, COLOMBO A, SANDRI MT, LAMANTIA G, COLOMBO N, CIVELLI M, MARTINELLI G, VEGLIA F, FIORENTINI C, CIPOLLA CM: Prevention of high-dose chemotherapy-induced cardiotoxicity in high-risk patients by angiotensin-converting enzyme inhibition. Circulation 114: 2474-2481, 2006.

COLAN SD, PARNESS IA, SPEVAK PJ, SANDERS SP: Developmental modulation of myocardial mechanics: ageand growth-related alterations in afterload and contractility. J Am Coll Cardiol 19: 619-629, 1992.

CORNÉLISSEN G, BAKKEN E, DELMORE P, ORTH-GOMÉR K, AKERSTEDT T, CARANDENTE O, CARANDENTE F, HALBERG F: From various kinds of heart rate variability to chronocardiology. Am J Cardiol 66: 863-868, 1990.

EKHOLM E, RANTANEN V, BERGMAN M, VESALAINEN R, ANTILA K, SALMINEN E: Docetaxel and autonomic cardiovascular control in anthracycline treated breast cancer patients. Anticancer Res 20: 2045 2048, 2000.

ELBL L, HRSTKOVÁ H, TOMÁŠKOVÁ I, BLAŽEK B, MICHÁLEK J: Long-term serial echocardiographic examination of late anthracycline cardiotoxicity and its prevention by dexrazoxane in pediatric patients. Eur $J$ Pediatr 164: 678-684, 2005.

ELBL L, HRSTKOVÁ H, TOMÁŠKOVÁ I, MICHÁLEK J: Late anthracycline cardiotoxicity protection by dexrazoxane (ICRF) in pediatric patients: echocardiographic follow up. Support Care Cancer 14: 128-136, 2006.

GERŠL V, BAJGAR J, KRS O, HRDINA R, PALIČKA V, MAZUROVÁ Y: Changes in cholinesterase activities after daunorubicin administration to rabbits. Hum Exp Toxicol 15: 834-838, 1996.

GIANTRIS A, ABDURRAHMAN L, HINKLE A, ASSELIN B, LIPSHULTZ SE: Anthracycline-induced cardiotoxicity in children and young adults. Crit Rev Oncol Hematol 27: 53-68, 1998.

HORÁČEK JM, PUDIL R, TICHÝ M, JEBAVÝ L, STARSOVÁ A, PRAUS R, ŽÁK P, MALÝ J: The use of biochemical markers in cardiotoxicity monitoring in patients treated for leukaemia. Neoplasma 52: 430-434, 2005. 
HRSTKOVÁ H, HONZÍKOVÁ N, FIŠER B, NOVÁKOVÁ Z: Baroreflex sensitivity, blood pressure and heart rate variability in children and adolescents after anthracycline treatment. Scripta Med 74: 187-194, 2001.

HRSTKOVÁ H, HONZÍKOVÁ N, NOVÁKOVÁ Z, ZÁVODNÁ E: Some circulatory parameters in children after antitumour therapy. In: Chronobiological Analysis in Pathophysiology of Cardiovascular System. F HALBERG, T KENNER, J SIEGELOVÁ (eds), NCO NZO, Brno, 2003, pp 144-151.

JEMAL A, SIEGEL R, WARD E, MURRAY T, XU J, SMIGAL C, THUN MJ: Cancer statistics. CA Cancer J Clin 56: 106-130, 2006.

LIPSHULTZ SE, LIPSITZ SR, SALLAN SE, DALTON VM, MONE SM, GELBER RD, COLAN SDE: Chronic progressive cardiac dysfunction years after doxorubicin therapy for childhood acute lymphoblastic leukemia. J Clin Oncol 23: 2629-2636, 2005.

MERTENS AC, YASUI Y, NEGLIA JP, POTTER JD, NESBIT ME JR, RUCCIONE K, SMITHSON WA, ROBISON LL: Late mortality experience in five-year survivors of childhood and adolescent cancer: the Childhood Cancer Survivor Study. J Clin Oncol 19: 3163-3172, 2001.

MLADOSIEVIČOVÁ B, FOLTINOVÁ A, PETRÁŠOVÁ H, BERNADIČ M, HULÍN I: Signal averaged electrocardiography in survivors of Hodgkin's disease treated with and without dexrazoxane. Neoplasma 48: 61-65, 2001.

MOTT MG: Anthracycline cardiotoxicity and its prevention: Challenges and opportunities. Pediatr Oncol 824: 221228, 1997.

NOVÁKOVÁ Z, BALCÁRKOVÁ P, HONZÍKOVÁ N, FIŠER B, ZÁVODNÁ E, HRSTKOVÁ H, KRONTORÁDOVÁ K, ŠŤASTNÁ J: Arterial blood pressure and baroreflex sensitivity 1-18 years after completing anthracycline therapy. Neoplasma 54: 162-167, 2007.

OEFFINGER KC, MERTENS AC, SKLAR CA, KAWASHIMA T, HUDSON MM, MEADOWS AT, FRIEDMAN DL, MARINA N, HOBBIE W, KADAN-LOTTICK NS, SCHWARTZ CL, LEISENRING W, ROBISON LL: Chronic health condition in adult survivors of childhood cancer. N Engl J Med 355: 1572-1582, 2006.

PAI VB, NAHATA MC: Cardiotoxicity of chemotherapeutic agents. Drug Saf 22: 263-302, 2000.

SAKAI T, INAGKI R, TANIGUCHI T, SHINOZUKA K, KUNITOMO M, HAYASHI N, ISHII Y, MURAMATSU I: Persistent release of noradrenaline caused by anticancer drug 4 '-epidoxorubicin in rat tail artery in vitro. Eur $J$ Pharmacol 356: 25-30, 1998.

SCULLY RE, LIPSHULTZ SE: Anthracycline cardiotoxicity in long-term survivors of childhood cancer. Cardiovasc Toxicol 7: 122-128, 2007.

SIMBRE VC, DUFFY SA, DADLANI GH, MILLER TL, LIPSHULTZ SE: Cardiotoxicity of cancer chemotherapy. Implications for children. Pediatr Drugs 7: 187-202, 2005.

TANAKA H, THULESIUS O, YAMAGUCHI H, MINO M, KONISHI K: Continuous non-invasive finger blood pressure monitoring in children. Acta Paediatr 83: 646-652, 1994.

ZÁVODNÁ E, HRSTKOVÁ H, HONZÍKOVÁ N, NOVÁKOVÁ Z: Autonomous regulation of circulation in children after anthracycline therapy. Scripta Med 75: 195-202, 2002.

ZÁVODNÁ E, HRSTKOVÁ H, HONZÍKOVÁ N, NOVÁKOVÁ Z, FIŠER B: Physiological values of finger arterial pressure and baroreflex sensitivity for the age between 11-21 years. Physiol Res 54: 48P, 2005.

ZÁVODNÁ E, HRSTKOVÁ H, BALCÁRKOVÁ P, NOVÁKOVÁ Z, HONZÍKOVÁ N, FIŠER B: Blood pressure and baroreflex sensitivity after anthracycline chemotherapy in childhood with respect to fatty acid metabolism. Scripta Med 78: 257-264, 2005. 